\title{
Um breve panorama: descrição e abordagem metodológica de preposições no português brasileiro
}

\author{
Thatiana Ribeiro Vilela \\ Universidade Federal de São Paulo (UNIFESP), Guarulhos, São Paulo, Brasil \\ thatianatrv21@gmail.com \\ Elizabeth Gonçalves Lima Rocha \\ Universidade Federal de São Paulo (UNIFESP), Guarulhos, São Paulo, Brasil \\ bethroccha@hotmail.com
}

DOI: http://dx.doi.org/10.21165/el.v46i1.1761

\begin{abstract}
Resumo
O presente trabalho, ao traçar um breve panorama de estudos inscritos em diferentes vertentes que abordam a classe das preposições em $\mathrm{PB}$, propõe-se a examinar e discutir o tratamento de um conjunto de fenômenos a ela relacionados sob a ótica dos pressupostos teóricometodológicos adotados. Objetivamos mostrar que o estado atual dos trabalhos, cujas contribuições para o tema são indiscutíveis, por não fornecerem uma definição semântica unitária da preposição que responda pela variação atestada em seus diferentes usos ou por não se interessarem por alguns de seus empregos, permite levantar questionamentos envolvendo a problemática, os quais podem auxiliar na continuidade das pesquisas no campo.
\end{abstract}

Palavras-chave: preposições; semântica lexical; funcionamento enunciativo.

\section{A brief overview: description and methodological approach of prepositions in Brazilian Portuguese}

\begin{abstract}
This paper provides an overview of studies inscribed in different strands that approach the class of prepositions in BP, intends to examine and to discuss the treatment of a set of phenomena related to the class from the perspective of the theoretical and methodological assumptions adopted. The current circumstance of those works, whose contributions to the theme are indisputable, are yet limited. We consider that the works on the matter, for not attesting a unified semantic definition of the preposition that embraces the variation in use or for not considering some of its applications, give room to questionings that can add to the continuity of the researches.
\end{abstract}

Keywords: prepositions; lexical semantics; enunciation operation.

\section{Introdução}

De Vogüé (2011), ao compartilhar do pensamento de Lakatos, sustenta que, independentemente da natureza de um dado estudo, "é por meio do trabalho crítico de confronto entre teorias que os progressos científicos se efetuam" (DE VOGÜÉ, 2011, p. 282). Somente através desse exercício, executado de forma respeitosa e destituído de julgamentos e preconceitos, é possível "levantar hipóteses intuitivas, dar a essas hipóteses uma formulação exata, inferir suas consequências e confrontá-las com os fatos, para uma confirmação sempre provisória ou uma refutação" (ILARI, 1997, p. 15). Tal como esses autores, acreditamos nesse trabalho crítico e, sobretudo, no fato de que o 
exercício que ora propomos nos conduz, inevitavelmente, ao refinamento de nossa própria percepção em relação ao objeto examinado e à melhor exploração e compreensão do quadro teórico em que nos inserimos.

Este artigo dedica-se, portanto, de maneira pontual, a explorar como diferentes vertentes descrevem a classe das preposições e qual é a concepção de sentido adotada em cada uma. Julgamos ser de grande relevância analisar o sustentado por outras teorias e o modo como abordam fenômenos que almejamos examinar, como, por exemplo, a questão da delimitação do que vem a ser o termo antecedente à preposição, como e se são tratadas as questões relacionadas à semântica das preposições e qual a sua contribuição para a construção do sentido dos enunciados em que estão inseridas, etc. Dado o caráter preciso da investigação, focalizaremos apenas os seguintes aspectos: a) descrição do que é uma preposição; b) natureza do semantismo da preposição; c) descrição do modo como se apresentam os termos que cercam uma preposição (termos antecedente e consequente).

A organização do trabalho fundamenta-se na constatação da existência de dois movimentos epistemológicos: de um lado, vertentes teóricas distintas, mas que se aproximam por sustentar, para uma mesma preposição, um sentido de base, único ou polissêmico; de outro, uma vertente teórica para a qual não há sentido preposicional de base, mas, sim, um esquema de funcionamento de natureza relacional, responsável por explicar a variação semântica observada a cada vez que a preposição se insere discursivamente. Em moldes gerais, examinamos, antes, abordagens já consideradas canônicas, inscritas no primeiro movimento, por meio de obras ou trabalhos que figuram no cenário atual das investigações direcionadas ao grupo de palavras que apreendemos como preposição em $\mathrm{PB}$, para, na sequência, apresentar a vertente característica do segundo movimento, ainda pouco explorada nos estudos preposicionais em PB e à qual, por esta razão, dedicamos uma maior atenção.

Para tanto, no exame do primeiro movimento epistemológico, selecionamos quatro obras brasileiras de vertentes teóricas diferentes: na vertente tradicional, a obra de Lima (1974), tida como eixo norteador para muitos estudos, o que justifica sua inclusão nesse panorama; na funcionalista, a de Neves (2000); na cognitivista, a de Ilari et al. (2015); e, por fim, na abordagem da semântica lexical, os trabalhos de Berg (2005, 2009). Já no exame do segundo movimento, selecionamos a obra de Franckel e Paillard (2007), inscrita no referencial da Teoria das Operações Enunciativas e representante da vertente enunciativa, na qual os trabalhos de Romero (2011, 2013) e Vilela (2016a), entre outros direcionados às preposições em PB, se fundamentam. Seguimos, na apresentação, a ordem aqui indicada.

\section{A vertente tradicional}

Assim como Franchi (2006), defendemos que a visão que se tem da vertente tradicional é, em parte, equivocada, o que não significa dizer que a eximimos de quaisquer tipos de falhas. Na verdade, uma observação cautelosa de algumas das obras assim descritas permite apontar que, apesar de determinadas variantes linguísticas não serem abordadas, ainda é possível encontrar, nelas, um conjunto de sistematizações as quais estão para além do "certo" e "errado", pois são constituídas de traços descritivos em sua composição. 
Na obra de Lima (1974), as preposições são concebidas como palavras invariantes que subordinam um termo da frase a outro: "a preposição mostra que entre o antecedente e o consequente há uma relação, de tal modo que o sentido do primeiro é explicado ou completado pelo segundo" (LIMA, 1974, p. 157), sendo, portanto, "ofício das preposições subordinar um elemento da frase a outro, apresentando o segundo como complemento do primeiro" (LIMA, 1974, p. 157, grifos do autor).

No tocante à delimitação dos termos que cercam a preposição, o que vem a ser o antecedente é apontado como a palavra ou núcleo cujo sentido é condicionado a modificações pelo elemento que segue a preposição - o termo consequente. É importante destacar que o autor não especifica o que seriam essas modificações e quais os seus efeitos num dado enunciado. Apontar o termo antecedente como um termo "condicionado a modificações" não nos parece, portanto, suficiente, pois, por exemplo, nos casos de adjunção, como explicar essa "condição", uma vez que há elementos que já possuem um sentido completo segundo a gramática normativa? Posto que os elementos que integram um enunciado se relacionam e interagem para a construção de sentido, não estariam, então, todos esses elementos condicionados a modificações?

Como diferencial da obra, verificamos a busca pela compreensão de questões a respeito da semântica das preposições, enfoque comumente deixado de lado por abordagens desta vertente, descrevendo-as como fortes e fracas. As preposições fortes, tais como contra, entre e sobre, "guardam certa significação em si mesmas", enquanto as fracas, tais como $a$, com e de, "não têm sentido nenhum, expressando tão somente, em estado potencial e de forma indeterminada, um sentimento de relação" (LIMA, 1974, p. 321, grifos do autor). Neste último caso, concretiza-se apenas no contexto um dado valor significativo nas relações que podem estabelecer.

Em resumo, Lima (1974) aponta, em primeiro lugar, que as preposições são responsáveis por subordinar dois termos, antecedente e consequente, destacando suas características (condicionado ou não a modificações) e que, nesta subordinação, as preposições denotam cinco tipos fundamentais de relação: lugar, tempo, modo, instrumento, causa e fim; em segundo lugar, ao descrevê-las, estabelece a divisão das preposições entre fortes e fracas, sem esclarecer o porquê de algumas preposições guardarem sentido em si mesmas e de outras preposições estabelecerem apenas relações, concretizando valores significativos somente em contexto. Assim, embora o autor trate de cada uma das preposições de maneira individual, forneça, quando fortes, uma gama de sentidos que lhe são próprios e, por fim, mostre, quando fracas ou fortes, os tipos de relações que podem ser estabelecidas, a definição apresentada não se sustenta, visto que não se pode resumir os exemplos e sentidos listados à enorme variedade de usos que as preposições apresentam.

\section{A vertente funcionalista}

$\mathrm{Na}$ perspectiva de Neves (2000), as preposições são definidas como itens gramaticais que pertencem à esfera das relações e processos e atuam na junção dos elementos do discurso, sendo divididas em três grupos distintos: a) preposições introdutoras de argumentos ( $a$, até, com, contra, de, em, entre, para, por, sob e sobre); b) preposições não introdutoras de argumentos (ante, após, perante e sem); c) preposições acidentais, que consistem em unidades linguísticas pertencentes a outras classes gramaticais que podem, por sofrer um processo de gramaticalização, operar como uma preposição em determinados contextos. 
No que se refere a seu funcionamento, as preposições podem integrar duas situações distintas: dentro do sistema de transitividade, comportando-se como complemento verbal (i.e. como objeto direto, complemento de verbos transitivos indiretos, que se liga ao verbo necessariamente por meio de preposição), complementos nominais (i.e. como complemento de adjetivo, de substantivo), complemento de advérbio que também são precedidos de preposição; ou fora do sistema de transitividade, em que operam como um adjunto adnominal, adverbial ou quaisquer outras funções diferentes das de complemento. O sentido de uma preposição, como no caso de outros itens da língua, é definido no uso, no nível do texto. Assim, ao atuar dentro do sistema de transitividade, a preposição "tira seu valor das relações contraídas entre os elementos cuja junção ela efetua" (NEVES, 2000, p. 18); já quando opera fora do sistema de transitividade, a preposição pode, sim, estabelecer relações semânticas.

É interessante observar que, embora estabeleça uma divisão para distinguir o funcionamento das preposições de duas formas, Neves (2000) destaca que, para descrevê-las, é necessário considerar: "o seu valor unitário"; "a natureza dos termos em relação"; "a relação sintática entre o antecedente e o consequente"; "os traços semânticos dos dois termos em relação e a relação semântica que entre eles se estabelece" (NEVES, 2000, p. 18). Vale notar, entretanto, que "o seu valor unitário" não é efetivamente explorado durante a discussão dos exemplos ${ }^{1}$ e a única evidência a respeito da natureza desse "sentido único" das preposições repousa no fato de que, a partir das ocorrências do uso e da relação desses itens com o texto, é possível assumir significado ou definir quaisquer funções.

Da proposta trazida, verificamos que, sem desprezar o grande mérito desta obra, a qual se propõe a analisar os usos da língua e a abordar as unidades linguísticas por meio da observação de um considerável conjunto de exemplos, a Gramática de usos do português (NEVES, 2000) pode se aproximar de gramáticas tradicionais em muitos aspectos, como, por exemplo: propor a existência de um "sentido unitário", mas não discuti-lo ou considerá-lo durante a exploração dos exemplos, o que também se observa em Cunha e Cintra $(2008)^{2}$; deixar de fazer aproximações entre as descrições fornecidas e os exemplos das preposições em seus usos variados; não evidenciar quais são os termos antecedente e consequente, nem de que maneira interagem quando colocados em relação pela preposição; por partir de um funcionamento estritamente de ordem sintática (pertencer ou não ao sistema de transitividade) e afirmar, a partir dessa constatação, que a preposição ora possui sentido, ora não possui, coloca-se em dúvida a própria existência de um "sentido unitário" por ela sustentada, e isso pelo fato de tal sentido unitário não ser considerado quando ocorre seu esvaziamento em situações nas quais a preposição opera apenas como item relacional.

\footnotetext{
${ }^{1}$ Ver Romero $(2011,2013)$ para um maior aprofundamento dessa questão.

2 Tal obra, inscrita na vertente tradicional, não foi analisada neste artigo. Contudo, também apresenta um estudo interessante a respeito das preposições brasileiras, conforme discutido em Vilela (2016a).
} 


\section{A vertente cognitivista}

A obra organizada por Rodolfo Ilari $(2015)^{3}$ dedica-se a analisar as palavras de classe fechada, grupo do qual as preposições fazem parte. Os autores do capítulo dedicado às preposições defendem que essas unidades são predicadoras relacionais, pois relacionam duas entidades, a saber, figura e fundo (objeto em foco e termo de referência) (ILARI et al., 2015, p. 203), e que seu sentido é explicado por uma relação de polissemia e não de homonímia. Haveria, portanto, um sentido prototípico - de ordem espacial - e os demais sentidos observados seriam resultantes de extensões desse sentido "de base".

Considerando que uma preposição relaciona duas entidades, é possível perceber que essa "base espacial" corresponde à localização de um elemento no espaço/tempo em relação a um ponto de referência. A tentativa de compreender os variados sentidos adquiridos por uma preposição é orientada pela perspectiva cognitiva da linguagem, que possui recursos para explicar como esse processo ocorre, e pelo próprio processo de gramaticalização que, segundo eles, pode ser um forte aliado para recuperar o percurso histórico das preposições, cujos indícios são observados até nos usos atuais.

O cognitivismo busca explicar a linguagem por meio da cognição humana. No domínio das preposições, são mobilizadas três bases de conhecimento: imagético, modelos cognitivos idealizados e a própria língua como base do conhecimento. Essas bases são conduzidas pelas habilidades cognitivas através de recursos comparativos.

De maneira bastante sucinta, os esquemas imagéticos remetem à percepção de si e do próprio ambiente. Os modelos cognitivos idealizados consistem em construções conceituais que nos permitem formular a compreensão do mundo, consolidando, assim, as categorias e expressões capazes de descrevê-lo.

A língua é tratada como base de conhecimento. Ela proporciona bases para a comunicação através de recursos lexicais e morfossintáticos, e é por meio dela que moldamos nossos modelos cognitivos idealizados, pois ela nos fornece subsídios para saber quais experiências podem ou não ser percebidas dentro de um determinado contexto cultural, e para estabelecer limites metafóricos a determinados sentidos (por exemplo, tempo e espaço) (ILARI et al., 2015, p. 190).

Como mencionamos, os autores defendem a ideia de as preposições possuirem

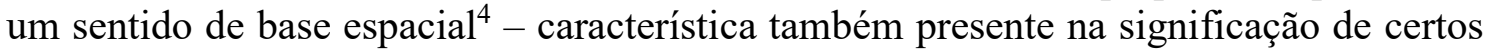
verbos, por exemplo, as preposições de e para e os verbos ir e vir -, que pode transportar-se também para o domínio temporal. Tal fenômeno, ao lado da metáfora, é denominado transposição de esquemas, e institui sentidos outros que podem ou não

\footnotetext{
${ }^{3} \mathrm{Na}$ introdução dessa gramática, Rodolfo Ilari faz menção à variedade de autores e à diversidade de referenciais teóricos que acabaram por influenciar a composição da obra justamente por conta da trajetória dos próprios pesquisadores envolvidos. Pontualmente, Ilari destaca a influência das vertentes funcionalista e gerativista; todavia, no capítulo dedicado às preposições, fica bastante evidente que o enfoque dado ao estudo é de natureza cognitivista e, face a isso, optamos por denominá-la como “cognitivista". É preciso, contudo, justificar que, mesmo com a predominância cognitivista, é possível encontrar, nele, aspectos da teoria multissistêmica de Ataliba T. de Castilho.

4 As relações espaciais não são representadas apenas por meio das preposições e as preposições não representam somente relações espaciais. Por isso, no estudo das preposições, é necessário considerar outras unidades linguísticas que também englobam a noção de espaço em suas características.
} 
trazer consigo resquícios do seu sentido originário ou prototípico. Aqui, para que outros sentidos proliferem por meio de metáforas, é necessário que esse sentido primeiro, bem como o seu uso, estejam consolidados. Dessa forma, os autores justificam:

É por isso que, do ponto de vista conceitual, a classe das preposições é fechada, para que seus elementos tenham um sentido de base bem estabelecido e possam ser usados em relações metafóricas. Conhecer a fundo o funcionamento das palavras de uma classe fechada revela muito sobre a estrutura de uma língua, e é uma boa maneira de entender o mecanismo de transposição de esquemas, cujo uso em qualquer língua é um fenômeno muito mais geral. (ILARI et al., 2015, p. 192).

Da análise realizada, concluímos destacando que, se os autores, no início, mencionam a existência de um sentido prototípico de base, nem sempre esse sentido é evidente no conjunto de exemplos selecionados, pois apresentam mais de um valor durante a descrição proposta; são tratados apenas os usos mais importantes das preposições, ou seja, os que fazem parte do conhecimento cognitivo dos falantes. Dessa forma, falta explorar exemplos considerados como expressões idiomáticas. Tais usos, constantes, poderiam fazer parte da identidade de uma preposição como qualquer outro tipo de sentença, uma vez que, como os próprios autores afirmam, os usos metafóricos ${ }^{5}$ são advindos do sentido que apontam como o de base.

\section{A vertente da semântica lexical}

O estudo ora abordado faz parte dos trabalhos de grande relevância por nós selecionados. No entanto, diferentemente das obras antes analisadas, tem-se aqui um trabalho que toma como ponto de partida questões ligadas à semântica e não à sintaxe.

O objetivo central do estudo de Berg (2005) consiste em descrever o comportamento semântico-lexical das preposições do $\mathrm{PB}$, atentando-se para o conteúdo semântico dos papéis temáticos ${ }^{6}$ dessas preposições. A autora conduz suas análises buscando responder a três questões, que são: saber se as preposições têm sentido, quais são esses sentidos e se são predicadoras. Para ela, responder a essas questões implica considerar, fundamentalmente, o conteúdo semântico dos papéis temáticos.

$\mathrm{Na}$ pesquisa desenvolvida, são priorizados apenas dois ambientes sintáticos em que a preposição ocorre: como objeto indireto e adjunto adverbial. As demais ocorrências são descartadas, como quando encabeçam complementos nominais, adjuntos adnominais, predicativos ou nos empregos caracterizados como expressões idiomáticas.

De saída, a autora afirma que nem todas as preposições são capazes de atribuir papel temático, mas que, independentemente desse fator, todas as preposições têm

\footnotetext{
${ }^{5}$ Destacamos que usos metafóricos devem, aqui, ser compreendidos não como uma figura de linguagem, mas como usos que seriam originados com base em um sentido primeiro (sentido prototípico).

${ }^{6} \mathrm{Na}$ semântica lexical, compreende-se a noção de papel temático como a relação de sentido estabelecida entre um dado item lexical e seu predicador, entre o verbo e seus argumentos (sujeito e complementos). Para a abordagem, não somente verbos podem atribuir papel temático, mas também os seus argumentos. Os papéis temáticos têm sido alvo de estudos por diferentes correntes teóricas. Por exemplo, ocupa um lugar central da teoria de Princípios e Parâmetros, de Noam Chomsky - que denomina como CritérioTheta. Tal critério estabelece que deve haver a existência de uma correspondência entre os sintagmas nominais e os papéis temáticos, ou seja, cada sintagma da sentença recebe apenas um papel temático e cada papel temático é associado a apenas um sintagma (CANÇADO, 2013, p. 8).
} 
sentido, algumas possuindo, porém, uma gama de sentidos mais específica do que outras. Assim como Lima (1974) e apoiando-se nas próprias acepções do gramático, assinala uma divisão para as preposições como fracas e fortes. As preposições $a$, com, de, em, para e por são consideradas fracas, possuindo mais variedade de sentido do que as demais; porém, é uma tarefa árdua estabelecer seu sentido fora do contexto em que estão inseridas; já as preposições ante, após, até, contra, desde, entre, perante, sem, sob, sobre são consideradas fortes e são mais previsíveis, uma vez que, mesmo fora do contexto, é possível atribuir-lhes um - ou poucos - sentidos mais bem demarcados.

Vale notar que a autora se compromete a discutir o porquê de algumas preposições, em certos ambientes, serem responsáveis por atribuir papéis temáticos e, em outros, não o fazer. Face a esse posicionamento, faz hipótese central de que todas as preposições, independentemente do ambiente em que se inserem, possuem sentido; em relação à atribuição dos papéis temáticos, afirma que as preposições podem, a depender do verbo com o qual ocorrem, atuar em duas funções: como uma preposição predicadora e como uma preposição funcional. As preposições predicadoras encabeçam argumentos que não são acarretados pelos verbos e atribuem papel temático a seus complementos, papel temático que nada tem a ver com o sentido intrínseco da preposição, mas com o tipo de ambiente semântico em que ela ocorre; já as funcionais encabeçam argumentos lógicos ${ }^{7}$ acarretados pelos verbos, e não são responsáveis pela atribuição de papel temático, cabendo ao verbo a respectiva função.

Notamos que Berg (2005), assim como em outras obras que analisamos, também propõe que as preposições possuem um sentido básico, mas atenta para o fato de que esse sentido de base, quando tomado isoladamente, não corresponde ao conteúdo semântico do papel temático e nem sempre estará relacionado com o sentido das propriedades semânticas ${ }^{8}$. Não por mera coincidência entre os sentidos dos elementos que acompanham a preposição, a autora afirma que os sentidos das preposições têm, sim, forte ligação com o verbo ou o nome que as acompanha e, no caso das preposições funcionais, seu sentido pode se aproximar semanticamente ao de papel temático dos argumentos acarretados pelo verbo predicador (BERG, 2005). Diante dessa constatação, ainda que se tratando de uma preposição forte cujos sentidos são mais bem demarcados, perguntamo-nos se não estariam, aqui, sendo apontados os sentidos das relações das quais as preposições fazem parte. Em que consistiria, então, o sentido básico das preposições, dado também levantado pela autora? Destacamos que o recurso de conferir a uma preposição elementos de sentido naturais de outras unidades é fortemente utilizado em outras abordagens para descrever o seu comportamento; no entanto, durante esse processo, não conseguimos verificar em que consiste exatamente o sentido das preposições, uma vez que toda a descrição acaba sendo tomada pela influência do semantismo de outras unidades. Nesse aspecto, a visão apresentada por Berg (2005) não

\footnotetext{
7 Tais argumentos não são vinculados às noções de complemento e adjunto presentes na gramática tradicional, mas estão relacionados à estrutura conceitual do predicador e possuem natureza semântica.

8 As propriedades semânticas são o conjunto de propriedades determinadas a partir das "relações sistemáticas entre palavras e sentenças" (CANÇADO, 2015, p. 162). Conforme aponta Berg (2005), "o sentido das propriedades semânticas emerge da composição entre o sentido da preposição, mais o sentido do argumento em que ela está inserida, mais o verbo da sentença" (BERG, 2005, p. 121). Sendo assim, os papéis temáticos são definidos por um grupo de propriedades semânticas que foram estabelecidas a partir da classe dos verbos e, no português brasileiro, quatro delas são fundamentais: desencadeador, afetado, estativo e controle.
} 
se afasta, por exemplo, da de Neves (2000), que também lança mão de elementos de sentido de outras unidades para tratar do sentido das preposições.

Considerando que a natureza predicadora das preposições é diferente da que ocorre com os verbos, essas unidades possuem argumentos que não são acarretados pelos verbos e são elas próprias as responsáveis pela atribuição de papel temático. Observemos o exemplo abaixo:

João viajou com sua namorada

Em (01), o SN "sua namorada” não é um argumento acarretado pelo verbo, pois o verbo "viajar" não remete à ideia de que necessariamente é preciso "viajar com alguém"; portanto, o SN "sua namorada" é argumento da preposição COM. A autora explica que o papel temático de uma preposição será produto de um movimento de composição entre a relação do predicador e o seu complemento, mais a composição desse predicador complexo com o verbo que predica a sentença - principalmente se estivermos lidando com uma preposição fraca.

As preposições funcionais não atribuem papel temático e, neste caso, como o verbo opera como predicador da sentença, é o responsável por atribuí-lo. De outro modo, quando funcionais, o sentido que essas preposições possuem deverá ser fundamentalmente compatível com o papel temático do argumento acarretado pelo verbo. Preposições funcionais também podem ser caracterizadas como "preposições inerentes", as quais parecem ser incorporadas aos verbos, tamanha a frequência com que figuram os mesmos ambientes. Um exemplo seria o do verbo concordar e a preposição com.

(02) Rosa concorda com a Maria

Trata-se de verbos que admitem a utilização de uma preposição específica, ocorrendo, geralmente, com preposições fracas.

Do estabelecimento das propriedades semânticas das preposições fracas, Berg (2005, p. 98) mostra que:

[...] a correlação entre os sentidos dessas preposições e as propriedades semânticas acarretadas pelos SPs que elas encabeçam são diretamente relacionados. Acreditamos que essa estreita correlação se deve ao fato de que o sentido dessas preposições é estabelecido pela própria composição da sentença, assim como as propriedades semânticas dos SPs, que são estabelecidas pela composição do sentido básico da preposição, mais o sentido do argumento em que ela está inserida, mais o sentido do verbo da sentença.

Embora proponha um trabalho bastante cuidadoso e minucioso tratando de um conjunto de preposições em PB, uma a uma, pelo viés da semântica, a tese de Berg ainda nos permite levantar algumas questões. Em primeiro lugar, o sentido das preposições nunca está nas próprias preposições? A pergunta se faz necessária pelo fato de o sentido ser apresentado ora como um produto da relação que estabelece com o seu complemento, quando a preposição funciona como um predicador complexo, ora como retirado do papel temático dos argumentos acarretados pelos verbos quando seu papel é funcional. Destacamos, ainda, que, tendo a autora estabelecido que o sentido dos papéis temáticos não se relaciona com o sentido das preposições, não é possível compreender 
quais são os limites existentes entre esses sentidos, pois quando realizamos uma leitura dos exemplos e das análises, esses sentidos muito se aproximam, quando não chegam a se confundir. Em segundo, em quais aspectos a abordagem da semântica lexical se distancia da abordagem funcionalista, uma vez que ambas as propostas conferem às preposições elementos de sentido oriundos de outras unidades, como, por exemplo, o verbo? Vale dizer, ainda, que, assim como faz Ilari et al. (2015), Berg (2015) exclui outros usos das preposições. Tais empregos não poderiam contribuir para revelar aspectos importantes a respeito do comportamento dessas unidades?

\section{A vertente enunciativa}

Fazendo um balanço das pesquisas até então expostas, observa-se a existência de grandes questões envolvidas no estudo da semântica preposicional e que dizem respeito à definição semântica da preposição, ao modo como essa definição explica os sentidos por ela adquiridos em discurso e à relação entre a "preposição Y" (termo consequente) e o termo X, antecedente a ser definido. Como se dão a relação, complementação e/ou subordinação entre os elementos que cercam a preposição? Tais elementos sempre se apresentam materializados no enunciado? Pode uma mesma preposição ter e não ter sentido em seus empregos? Em que consiste a identidade semântica de uma preposição?

Como fundamento para as discussões ora propostas, buscamos apoio em outra abordagem teórica, a saber, a Teoria das Operações Enunciativas (CULIOLI, 1999; DE VOGÜÉ, FRANCKEL, PAILLARD, 2011) e nos estudos acerca da semântica preposicional trazidos pela obra Grammaire des prépositions (FRANCKEL, PAILLARD, 2007), referencial para o qual não existem conteúdos anteriores ao uso da língua e, sim, uma identidade semântica de base relacional específica a uma dada preposição e que responde à variação observada a cada vez que dá seu emprego. Assim, para a compreensão do funcionamento de uma preposição, bem como do papel semântico que lhe é próprio, os autores apontam para a necessidade de se recorrer a um exame minucioso de seus usos, em número o mais variado possível, antes de formalizar a descrição que responda pela gama de sentidos originados na enunciação.

Partindo da constatação de que as unidades mais usuais da língua têm uma significação variável em função do enunciado, a caracterização da unidade linguística deve levar em conta a variabilidade das relações estabelecidas entre esta e seu(s) cotexto(s), isto é, o meio na qual se encontra inserida. Falar de relações unidade linguística-cotexto ${ }^{9}$ implica uma compreensão dinâmica do processo de significação. Em um enunciado, pelo fato de as unidades que o compõem participarem ativamente da construção de sua interpretação, assume-se que a estabilização semântica de uma dada unidade - no caso, da preposição -, realiza-se pela e na própria interação, não existindo sentido prévio que lhe seja conferido ou sentidos anteriores à interação observada.

Considerando que a variação de sentidos de uma unidade provém da unidade em si e de seu cotexto, a definição que a caracteriza se encontra não em sentidos ou conteúdos extraídos desses elementos, mas em operações de linguagem que fazem cada uma das unidades em jogo ser apreendida como pólos de regulação de suas interações com o cotexto. No que se refere à preposição, esta não será apreendida como a tradução de um sentido que existiria independentemente do próprio material verbal no qual ela se

\footnotetext{
9 O termo cotexto indica, aqui, se tratar da materialidade textual, do enunciado no qual se insere o sintagma preposicionado e sobre o qual se atua, e não do contexto extralinguístico ou situacional.
} 
insere, o que atesta a impossibilidade de identificá-la, semanticamente, por meio de "sentidos de base" dos quais outros sentidos decorreriam por extensões. Como explica Franckel (DE VOGÜÉ, FRANCKEL, PAILLARD, 2011, p. 22, grifo do autor):

[...] a identidade de uma unidade se define não por algum sentido de base, mas pelo papel especifico que ela desempenha nas interações constitutivas do sentido dos enunciados nos quais é ela posta em jogo. Esse papel é apreensível não como um sentido próprio da unidade, mas através da variação do resultado dessas interações. [...] o valor bruto da unidade é sempre um valor abstrato, uma épura, não uma designação, é um potencial e não um conteúdo.

Em outras palavras, se o sentido atribuído à preposição - quando esta se vê "dotada de sentido" - consiste no resultado de sua inserção discursiva, a sua definição (ou identidade semântica) deve ser buscada no próprio desenrolar do processo significativo, na interação que se verifica entre a preposição e os termos $\mathrm{X}$ e Y. A preposição é assim identificada por um funcionamento invariante, isto é, uma identidade semântica que lhe é própria, a definição de natureza metalinguística construída a partir da observação do próprio papel exercido pela preposição nas interações por ela integradas. Trata-se de uma representação de sua dinâmica de uso que só pode ser apreendida por meio da análise de diferentes empregos dos quais se deve dar conta.

Constituindo-se como uma constante de funcionamento que sustenta os empregos de uma preposição, a identidade semântica evidencia a regularidade da dinâmica observada a cada vez que essas unidades se inserem em um enunciado. São esquemas operatórios generalizáveis que se manifestam sempre no uso da preposição e que permitem compreender, para além das especificidades características da língua em uso e da ampla variação semântica que nela se faz presente, a sistematização necessária à reflexão gramatical. A natureza destes esquemas tem por fundamento a operação de orientação (CULIOLI, 1999) em sua articulação com operações postas em jogo pelas preposições: seja com a "divisão" do domínio de Y, termo que segue a preposição, em zonas, seja com o "discernimento" de $\mathrm{X}$, isto é, com o fato de $\mathrm{Y}$ atribuir a $\mathrm{X}$ propriedades que não necessariamente lhe dizem respeito. Sobre a operação de orientação, De Vogüé, Franckel e Paillard (2011, p. 91) salientam que: "Todo termo (em seu sentido mais amplo: sequência, frase, unidade lexical etc.) é tomado em relação a um outro termo, previamente dado, que tem, nessa relação sempre assimétrica, o estatuto de "orientador" [repère]".

Ainda no que tange à divisão do domínio de $\mathrm{Y}$ ou ao discernimento de $\mathrm{X}$, os autores têm sustentado que, enquanto a divisão implica, por parte da preposição em jogo, a associação de um domínio a Y (termo que a segue) a ser configurado em zonas que não decorrem necessariamente do espacial, bem como o estabelecimento de um vínculo entre $\mathrm{X}$ e a zona estabelecida, o discernimento implica um modo de apreensão de $\mathrm{X}$ por $\mathrm{Y}$ a partir da atribuição de determinadas propriedades que não teriam como definir X intrinsecamente, pelo fato de estas não serem suas propriedades constitutivas (FRANCKEL; PAILLARD, 2007).

A metodologia de análise dos enunciados fundamenta-se no cruzamento das duas ordens de operações acima entrevistas. Na relação X PREP Y, por ser $\mathrm{Y}$ considerado orientador da relação, trata-se de verificar qual termo será por ele orientado, uma vez que X não é um termo efetivamente presente no enunciado (não é, por exemplo, o verbo). Em linhas gerais, considerando a relação X PREP Y, assumimos 
que: $1^{\circ}$ ) se o termo $\mathrm{Y}$ (consequente) é o termo que segue a preposição, o termo $\mathrm{X}$ não é evidente, nem necessariamente explícito no enunciado. Há, portanto, uma relação assimétrica entre $\mathrm{X}$ e $\left.\mathrm{Y} ; 2^{\circ}\right) \mathrm{Y}$ confere determinações específicas a $\mathrm{X}$, termo a ser evidenciado, segundo a natureza da identidade semântica da preposição e o fato de ela ser uma preposição de divisão ou de discernimento. É assumido também que a interação VERBO-PREP decorre de uma combinatória entre dois predicados (o verbo e a preposição), com graus diferentes de imbricação entre os parâmetros próprios à identidade semântica de cada um ${ }^{10}$. Trata-se, ainda, de verificar qual relação (divisão ou discernimento) se observa e como representá-la em termos de uma identidade semântica, forma invariante que define uma dada preposição.

Visto que, nesta abordagem, o sentido das unidades linguísticas é definido pelo papel desempenhado na dinâmica de interação em que operam os elementos linguísticos do enunciado, pondera-se que tal sentido só será acessado por meio de reformulações e paráfrases cuidadosamente controladas, mecanismo denominado glosa.

A glosa consiste num tipo de reformulação em que o "acesso à identidade de uma unidade pode ser constituído pela análise metodologicamente controlada do papel que ela desempenha nos enunciados em que é colocada em jogo, papel analisado frente ao contexto convocado" (DE VOGÜÉ; FRANCKEL; PAILLARD, 2011). A glosa busca, assim, evidenciar a regularidade dinâmica observada a cada vez que a preposição se enuncia e isso por meio, por exemplo, da permutação ${ }^{11}$ de uma preposição com outras preposições (ver ex. 03), do confronto de enunciados diferentes que contenham a mesma preposição (ver ex. 04), do confronto entre enunciados aparentemente semelhantes (ver ex. 05), do confronto de enunciados em que se observam a presença ou ausência de preposição (ver ex. 06), e da análise das várias interpretações decorrentes de uma mesma construção (ver ex. 07), em que há o que se conhece por "ambiguidade": a) Potter me acompanhou na visita às docas; b) Potter é corretor de seguros e intermediou a minha visita às docas, pois me vendeu um pacote de viagem. São esses confrontos e manipulações que permitem formalizar características específicas de cada preposição e sua ampla variação semântica, como ilustramos abaixo:

Dividir doze maçãs COM/POR/ENTRE três pessoas.

(04) Eu concordei COM ele / Estava contaminado COM o vírus.

(05) Falei COM ela / Conversei COM ela.

(06) Mariana namora o Leo / Mariana namora COM o Leo.

(07) Contratei COM Potter uma visita às docas de Nelson.

Em suma, empenhamo-nos em pôr em prática estratégias de reformulação dos enunciados a partir de contextos discriminativos nos quais a preposição se faz ou não

\footnotetext{
10 Considerando que um dado verbo mobiliza parâmetros semânticos abstratos de um modo singular (ROMERO; TRAUZZOLA, 2014; ROMERO, 2017) e que a preposição apresenta uma identidade semântica de natureza relacional, dada a identidade que lhe é característica, observam-se relações em que "X e Y correspondem, ambos, a um parâmetro [evocado pelo] verbo, [ou então] [...] ou X, ou Y, ou nem X, nem Y, corresponde a um parâmetro [evocado pelo] verbo" (FRANCKEL; PAILLARD, 2007, p. 30). Ver, a esse respeito, Romero, Vilela e Alvarenga (no prelo).

${ }^{11} \mathrm{O}$ confronto entre duas sequências se deve ao fato de que as diferenças e aproximações de sentido são manifestadas no vai-e-vem das reformulações possíveis.
} 
presente ou é confrontada com outras preposições capazes de ocupar a sua posição na relação. É neste trabalho contínuo em que se opera sobre a linguagem que nos fundamentamos para recuperar o que há de invariante e sistemático em relação à significação de uma preposição - sua identidade semântica -, pois, ao confrontar enunciados com cada uma de suas reformulações possíveis, espera-se, "no exame das diferenças que se manifestam nesse vai-e-vem" de um enunciado à sua reformulação (DE VOGÜÉ; FRANCKEL; PAILLARD, 2011), delinear uma aproximação de suas propriedades semânticas constitutivas ${ }^{12}$.

\section{Considerações finais} examinadas.

Do exposto, decorre o quadro 1, que traz uma síntese das diferentes vertentes

Quadro 1. Síntese dos aspectos analisados

\begin{tabular}{|c|c|c|c|c|c|}
\hline & $\begin{array}{l}\text { LIMA } \\
\text { (1974) }\end{array}$ & $\begin{array}{l}\text { NEVES } \\
(2000)\end{array}$ & $\begin{array}{l}\text { ILARI et al. } \\
\text { (2015) }\end{array}$ & $\begin{array}{l}\text { BERG } \\
(2005)\end{array}$ & $\begin{array}{l}\text { FRANCKEL, } \\
\text { PAILLARD } \\
(2007)\end{array}$ \\
\hline $\begin{array}{l}\text { Descrição do } \\
\text { que é uma } \\
\text { preposição }\end{array}$ & $\begin{array}{l}\text { Palavra } \\
\text { invariante que } \\
\text { subordina um } \\
\text { termo da frase a } \\
\text { outro, sendo o } \\
\text { segundo termo } \\
\text { sempre } \\
\text { dependente do } \\
\text { primeiro. }\end{array}$ & \begin{tabular}{lr}
\multicolumn{2}{l}{ Palavra } \\
pertencente à \\
esfera das \\
relações & e \\
processos. & \\
Atuam & na \\
junção & de \\
elementos & do \\
discurso. &
\end{tabular} & $\begin{array}{l}\text { A preposição } \\
\text { é } \quad \text { uma } \\
\text { predicadora } \\
\text { relacional. }\end{array}$ & $\begin{array}{l}\text { A preposição } \\
\text { participa de } \\
\text { relações. É } \\
\text { caracterizada } \\
\text { como } \\
\text { predicadora ou } \\
\text { funcional. }\end{array}$ & $\begin{array}{l}\text { A preposição é } \\
\text { um relator R } \\
\text { em X(R)Y. Y, } \\
\text { orientador da } \\
\text { relação, } \\
\text { confere } \\
\text { determinações } \\
\text { a X. }\end{array}$ \\
\hline $\begin{array}{l}\text { Descrição do } \\
\text { modo de } \\
\text { apresentação } \\
\text { dos termos } \\
\text { antecedente e } \\
\text { consequente }\end{array}$ & $\begin{array}{l}\text { O antecedente é } \\
\text { a palavra que } \\
\text { opera como } \\
\text { núcleo na } \\
\text { construção e é a } \\
\text { que será } \\
\text { modificada pelo } \\
\text { termo } \\
\text { consequente, } \\
\text { complemento } \\
\text { que segue a } \\
\text { preposição. }\end{array}$ & $\begin{array}{l}\text { A natureza } \\
\text { dos termos } \\
\text { colocados em } \\
\text { relação e o } \\
\text { modo como } \\
\text { interagem são } \\
\text { considerados, } \\
\text { mas não são } \\
\text { explicitados } \\
\text { na } \\
\text { explanação. }\end{array}$ & $\begin{array}{l}\text { A preposição } \\
\text { atua } \\
\text { relação entre } \\
\text { entidades: } \\
\text { figura } \\
\text { fundo, i.e. } \\
\text { objeto em } \\
\text { foco e termo } \\
\text { de referência. } \\
\mathrm{Na} \text { relação, } \\
\text { figura e fundo } \\
\text { podem ser } \\
\text { objetos ou } \\
\text { eventos. }\end{array}$ & $\begin{array}{l}\text { A preposição } \\
\text { predicadora } \\
\text { encabeça } \\
\text { argumentos } \\
\text { que não são } \\
\text { acarretados } \\
\text { pelo verbo e } \\
\text { atribui papel } \\
\text { temático a seus } \\
\text { complementos; } \\
\text { a funcional } \\
\text { encabeça } \\
\text { argumentos } \\
\text { lógicos } \\
\text { acarretados } \\
\text { pelo verbo, e } \\
\text { não atribui } \\
\text { papel temático. }\end{array}$ & $\begin{array}{l}\text { X é o termo } \\
\text { antecedente e } \\
\text { Y, o termo } \\
\text { consequente. } \\
\text { Y é facilmente } \\
\text { identificável } \\
\text { no enunciado, } \\
\text { pois segue a } \\
\text { preposição. X } \\
\text { é de natureza } \\
\text { complexa e } \\
\text { demanda ser } \\
\text { recuperado, na } \\
\text { maioria dos } \\
\text { casos, por } \\
\text { meio ra da } \\
\text { própria } \\
\text { interação } \\
\text { verificada. }\end{array}$ \\
\hline $\begin{array}{l}\text { Natureza do } \\
\text { semantismo } \\
\text { da } \\
\text { preposição }\end{array}$ & $\begin{array}{l}\text { Há preposições } \\
\text { que guardam } \\
\text { sentidos em si } \\
\text { mesmas (fortes) } \\
\text { e outras que não } \\
\text { têm sentido, } \\
\text { expressando } \\
\text { unicamente um }\end{array}$ & $\begin{array}{l}\text { A natureza do } \\
\text { sentido da } \\
\text { preposição é } \\
\text { definida no } \\
\text { nível } \\
\text { intrafrásico. } \\
\text { Quando atua } \\
\text { dentro do } \\
\end{array}$ & $\begin{array}{lr}\text { Explica-se } & \text { o } \\
\text { sentido da } & \text { da } \\
\text { preposição } \\
\text { por uma } \\
\text { relação de } \\
\text { ordem } \\
\text { polissêmica. } \\
\text { Existe um }\end{array}$ & $\begin{array}{lr}\text { O } & \text { significado é } \\
\text { a combinação } \\
\text { de } r \text { sentido } \\
\text { somado } \\
\text { referência. } \\
\text { preposição } & \text { tem } \\
\text { sentido } & \text { em } \\
\text { todos } & \text { os } \\
\end{array}$ & $\begin{array}{l}\text { A preposição } \\
\text { tem uma } \\
\text { identidade } \\
\text { semântica cuja } \\
\text { natureza difere } \\
\text { daquela em } \\
\text { termos de um } \\
\text { conteúdo }\end{array}$ \\
\hline
\end{tabular}

${ }^{12}$ Ver, a esse respeito, Romero $(2011,2013)$ e Vilela (2016a). 


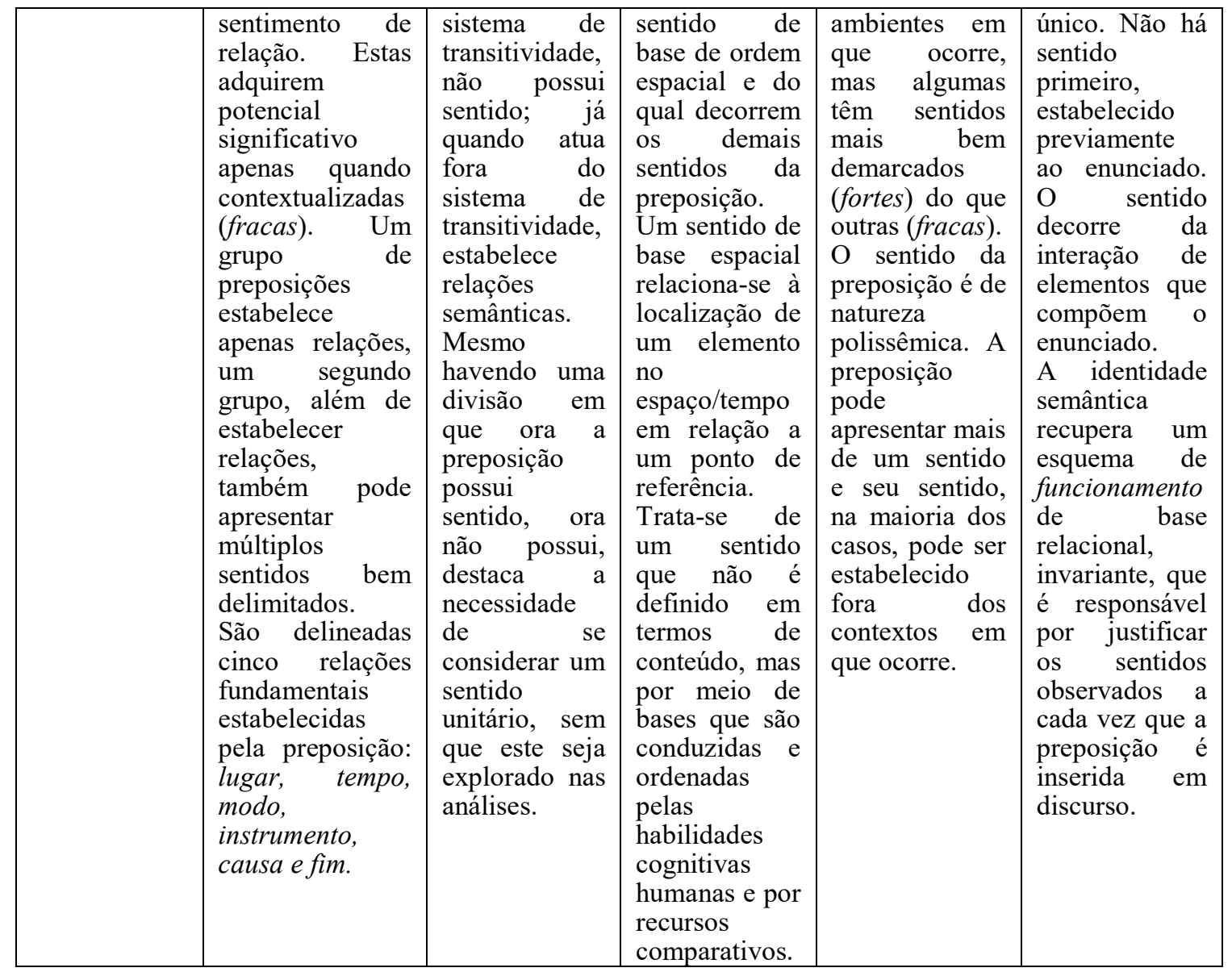

\section{Fonte: Produção dos autores}

O panorama traçado nos levou a examinar como ocorre a relação mediada por uma preposição que coloca em jogo a existência dos termos antecedente e consequente. Nessa relação, somos convocados a (re)pensar a materialidade do termo antecedente, pelo fato de haver a necessidade de recuperá-lo em casos em que ele não se encontra diretamente expresso no enunciado. Esse fato é um dos que, justamente, não são explorados pelas obras analisadas que, quando abordam tal questão, se limitam apenas a descrever a natureza morfológica desses termos, como o faz Lima (1974), e não o papel e os efeitos que desencadeiam na referida relação.

De maneira geral, sugerir a existência de um significado unitário ou de base não nos parece suficiente para compreender o funcionamento da preposição face a seus variados usos. A descrição de uma multiplicidade de sentidos também se mostra questionável quando se pensa na possibilidade de se alcançar a enumeração dos sentidos que uma preposição pode potencialmente apresentar.

Por fim, o aspecto mais instigante consiste em se considerar, para uma mesma preposição, uma possível flutuação semântica relacionada ao fato de ela poder ou não ter sentido. Se se assume a existência de um sentido de base ou um significado unitário que nos parece ser descrito como inerente a uma preposição, qual seria o fenômeno responsável por inibi-lo, ou ainda, por fazer desaparecer esse significado nos casos em que a preposição é tida como destituída de sentido? 
Embora estejamos diante de estudos que abordam a classe das preposições de maneira cuidadosa e vão além de apontar que essas unidades "ligam termos", ainda assim acreditamos que o estado atual das descrições nos permite levantar um leque interessante de questões, de um lado, por não fornecerem uma definição semântica unitária para cada preposição capaz de responder pela variação atestada em seus diferentes empregos, de outro, por não considerarem certo número de empregos. Por essas razões, demandam-se outras análises que possam contribuir para $o$ desenvolvimento da problemática.

Certamente, a vertente enunciativa à qual nos filiamos não está isenta de questionamentos. Entretanto, como temos defendido desde o início, o que interessa, neste artigo, não é simplesmente contestar, mas propor um exercício crítico e reflexivo que contribua para o avanço das pesquisas no campo. E, sem dúvida, embora os estudos aqui mencionados não esgotem o tema, eles são significativos e nos motivam na busca por respostas que tragam uma melhor compreensão dos problemas apontados.

\section{REFERÊNCIAS}

BERG, M. O comportamento semântico-lexical das preposições no português do Brasil. 2005. 128 f. Tese (Doutorado em Linguística) - Faculdade de Letras, Universidade Federal de Minas Gerais, Minas Gerais, 2005.

Relações predicativas das preposições. $A B R A L I N$, São João del Rei: UFSJ, v. 8, n. 2, p. 101-116, jul./dez. 2009.

CANÇADO, M. Os papéis temáticos. Manuscrito. 2013. Disponível em: $<$ http://www.letras.ufmg.br/profs/marciacancado/dados/arquivos/os\%20papeis\%20tema ticos.pdf $>$. Acesso em: 21 ago. 2014.

- Manual de Semântica: noções básicas e exercícios. 2. ed. São Paulo: Contexto, 2015.

CULIOLI, A. Pour une linguistique de l'énonciation: formalisation et opérations de repérage. Paris: Ophrys, 1999.

CUNHA, C.; CINTRA, L. Nova Gramática do Português Contemporâneo. 5. ed. Rio de Janeiro: Lexikon, 2008.

DE VOGÜÉ, S. Os princípios organizadores da variedade das construções verbais. ReVEL, v. 9, n. 16, p. 276-315, mar. 2011.

DE VOGÜÉ, S.; FRANCKEL, J.-J; PAILLARD, D. Linguagem e enunciação: representação, referenciação e regulação. São Paulo: Contexto, 2011.

FRANCKEL, J.-J.; PAILLARD, D. Grammaire des prépositions. Tome I. Paris: Ophrys, 2007.

FRANCHI, C. Mas o que é mesmo "gramática”? São Paulo: Parábola, 2006 [1977].

ILARI, R. A linguística e o ensino de língua portuguesa. 4. ed. São Paulo: Martins Fontes, 1997.

ILARI, R.; NEVES, M. H. M. Gramática do português culto falado no Brasil: classes de palavras e processos de construção. T.2, Campinas: Editora da UNICAMP, 2008. 
ILARI, R.; CASTILHO, A. T.; LEITÃO, M. L.; KLEPPA, L. A.; BASSO, R. M. A preposição. In: ILARI, R. (Org.). Gramática do português culto falado no Brasil: volume IV: palavras de classe fechada. São Paulo: Contexto, 2015. p. 163-310.

LIMA, C. H. da R. Gramática normativa da língua portuguesa. 17. ed. Rio de Janeiro: José Olímpio Editora, 1974.

NEVES, M. H. M. Gramática de usos do português. São Paulo: Editora UNESP, 2000.

POSSENTI, S. Discurso, estilo e subjetividade. São Paulo: Martins Fontes, 2008.

ROMERO, M. Le fonctionnement sémantique de la préposition POR en portugais brésilien. Faits de Langues, Les Cahiers, Paris: Ophrys, n. 3, p. 209-232, 2011.

Processos enunciativos e identidade semântica da preposição POR. Cadernos do IL, Porto Alegre, n. 46, p. 149-170, jun. 2013.

Léxico, invariancia y actividad de lenguaje. In. GARCÍA-MOLINS, A. L., JIMÉNEZ, D. J. (Ed.). Enacción y léxico. Valencia: Tirant Humanidades, 2017. p. 121-142.

ROMERO, M.; TRAUZZOLA, V. S. L. Identidade lexical, funcionamento enunciativo e variação semântica para a Teoria das Operações Enunciativas. Calidoscópio. Rio Grande do Sul, v. 12, n. 2, p. 239-248, mai./ago. 2014.

ROMERO, M.; VILELA, T. R. O uso interproposicional de POR em uma descrição unitária de funcionamento da preposição. In. DIAS, L. F. et alli (Org.) Enunciação e materialidade linguística. Belo Horizonte: Ed. UFMG, 2015. p. 6-18.

ROMERO, M.; VILELA, T. R.; ALVARENGA, C. D. M. ROMPER COM no português brasileiro: modos de integração da preposição COM à relação predicativa. $I I$ Seminário Enunciação e materialidade linguística. UFMG, 2016. (no prelo)

VILELA, T. R. Educação léxico-gramatical: um estudo semântico-enunciativo da preposição COM. 2016a. 190 f. Dissertação (Mestrado em Ciências) - Escola de Filosofia, Letras e Ciências Humanas, Universidade Federal de São Paulo, São Paulo, $2016 \mathrm{a}$.

Relatório Científico MS. Fundação de Amparo à Pesquisa do Estado de São Paulo (processo 2014/22458-1). 106f. São Paulo, 2016 b.

Recebido em: 07/11/2016

Aprovado em: 14/09/2017 